\title{
Sargadelos: patrimonio cultural, memorístico y turístico
}

Inmaculada Real López ${ }^{a}$

${ }^{\text {a } I n v e s t i g a d o r a ~ P o s t d o c t o r a l ~ J u a n ~ d e ~ l a ~ C i e r v a, ~ U n i v e r s i d a d ~ d e ~ Z a r a g o z a, ~ i n m a r e a l @ u n i z a r . e s ~}$

\begin{abstract}
Resumen
En este artículo se aborda la cerámica de Sargadelos desde la perspectiva de la identidad. Para ello se comienza analizando cuáles fueron sus orígenes y la evolución que esta producción ha tenido hasta la actualidad. Se destaca el carácter excepcional que ha conseguido esta loza gallega emprendida en el siglo XIX y que fue un exponente de modernidad. Díaz Pardo encuentra en este material un soporte donde dar visibilidad y rescatar un periodo cultural que había caído en el olvido. Un proceso de recuperación que concluyó, gracias al apoyo de los intelectuales exiliados en Argentina, con la creación del Laboratorio de Formas y la fabricación de una cerámica que se convierte en el símbolo de Galicia. Actualmente, la cerámica de Sargadelos es un reclamo turístico y ha conseguido tener eco a nivel nacional e internacional.
\end{abstract}

Palabras clave: Sargadelos, cerámica, memoria, identidad, turismo, Galicia.

\begin{abstract}
This article studies Sargadelos ceramics from an identity perspective. It begins by analyzing what were its origins and the evolution that this production has had until today. The exceptional character that this Galician earthenware undertaken in the nineteenth century and that was an exponent of modernity stands out. Díaz Pardo finds in this material a support where to give visibility and rescue a cultural period that had been forgotten. A recovery process that concluded, thanks to the support of exiled intellectuals in Argentina, with the creation of the Forms Laboratory and the manufacture of a ceramic that becomes the symbol of Galicia. Currently, Sargadelos pottery is a tourist attraction and has managed to echo nationally and internationally.
\end{abstract}

Keywords: Sargadelos, ceramic, memory, identity, tourism, Galicia. 


\section{Introducción}

En este artículo se presenta el proyecto cultural de Sargadelos, una iniciativa que estaba ligada a la recuperación de la identidad gallega, al mismo tiempo que rescataba la producción de cerámica impulsada por el Marqués de Sargadelos en el siglo XIX con la creación del primer alto horno privado de carácter civil. El marco en el que se produjo este resurgimiento fue durante la posguerra española, los años de la autarquía y el aislamiento político internacional que, además en Galicia estaba fuertemente acusado por un clima de empobrecimiento intelectual, debido a la desaparición del movimiento renovador como consecuencia de las represiones, incautaciones y exilios. Al artista Isaac Díaz Pardo se debe la idea de reactivar aquella exitosa fábrica lucense decimonónica con el fin de dinamizar el panorama cultural del noroeste español, dando lugar a un proyecto empresarial e interdisciplinar que terminaría integrando diseño, ingeniería, arquitectura, memoria, cultura y patrimonio, y que formaba parte del Laboratorio de Formas. Actualmente la producción de cerámica sigue activa, tras ocho décadas consecutivas sin interrupción que, pese a sus periodos de declive, ha sabido resurgir y consolidar su trayectoria.

El objetivo de este trabajo es presentar desde un punto de vista evolutivo, la conformación de un símbolo identitario enraizado en Galicia para comprender cómo se han ido incorporando y traduciendo diferentes elementos tradicionales que forman parte del patrimonio cultural gallego hasta convertirse en iconos del lenguaje más moderno del diseño. Un aspecto sobre el que se quiere hacer un especial énfasis es que, más allá del éxito que integra este proyecto, el cual embebe de la iconografía céltica, románica y barroca gallega; hay un aspecto que va mucho más allá de lo que se interpreta a simple vista, el estrecho vínculo que tiene con la memoria histórica por el puente cultural que Díaz Pardo construyó entre la Galicia del interior y los intelectuales gallegos exiliados en Argentina. Es a estos últimos a los que hay que atribuir el impulso internacional que la cerámica de Sargadelos adquirió en los años cincuenta, así como la renovación estética debido a los postulados que en materia de diseño se estaban desarrollando en Alemania y en Argentina, además se convirtieron en los transmisores de todas aquellas influencias, directas o indirectas, que procedían del exterior y que se fueron insertando en esta producción.

Desde sus orígenes, las localidades de O Cervo (Lugo) y Sada (La Coruña) acogieron los centros de fabricación de la cerámica junto a una intensa programación cultural de carácter interdisciplinar que idearon desde sus inicios. El reclamo de la población fue uno de los motores principales desde su fundación, pues querían integrarse en el territorio y expandirse reactivando la identidad a través de la producción de la loza gallega. Sin embargo, como consecuencia de los diferentes periodos de crisis que ha sufrido esta compleja empresa, ha buscado dirigirse a un público más diverso, a la vez que optaron por abrir las puertas de sus instalaciones a visitas turísticas. El valor artístico y patrimonial que integra Sargadelos ha quedado demostrado tras su declaración como Bien de Interés Cultural (BIC), y actualmente está en proceso de tramitación la protección de la colección y el edificio que alberga el Museo Gallego de Arte Contemporáneo Carlos Maside, también vinculado al Laboratorio de Formas. A día de hoy, Sargadelos es símbolo de Galicia, su expansión a nivel nacional e internacional ha favorecido la consolidación de una trayectoria que busca, a su vez, fomentar el turismo de la zona mediante la organización de visitas guiadas, las cuales acercan al público tanto al conjunto histórico-artístico de Sargadelos del siglo XIX, como a las actuales fábricas. Tradición y renovación son los adjetivos definidores de este complejo cultural que ha conseguido convertirse en uno de los emblemas de la modernidad gallega.

Para el desarrollo de este artículo se ha optado, en primer lugar, por una aproximación histórica de los orígenes de Sargadelos, con los que se busca explicar el enraizamiento que tiene este proyecto con el lugar convirtiéndose en clave de identidad que, más allá de la infraestructura industrial avanzada que en su día representó, existe una estrecha vinculación con el auge de una cultura gallega que tuvo su desarrollo en las primeras décadas del siglo XX. Perspectiva esencial que sirve para explicar el renacer cultural que se produjo tras el panorama desolador que ocasionó la Guerra Civil española. Isaac Díaz Pardo tomó el relevo del Marqués de Sargadelos y consiguió reemprender la cerámica ya desaparecida para convertirlo en un soporte iconográfico, ambos fueron dos figuras clave para la historia de Galicia. En el último apartado se expone la importancia que ha tenido el turismo para acercar al público esta producción cerámica, el acceso a sus instalaciones ha favorecido la difusión de este ambicioso proyecto cultural que se creó para el pueblo, pues es a él a quien se dirige esta producción. 


\section{La recuperación de la tradición, la identidad y la memoria. Los orígenes del proyecto a la actualidad}

La fábrica de Sargadelos, ubicada en el municipio de Cervo, en la provincia de Lugo, fue impulsada por Antonio Raimundo Ibáñez, popularmente conocido como Marqués de Sargadelos. Se trataba de una figura adelantada a la época, porque en la planificación industrial y empresarial utilizaba los recursos de la zona para favorecer la economía gallega, mientras en España aún había un modelo de producción obsoleto casi medievalista. El nuevo impulso que se daba se aproximaba al concepto de las empresas modernas, de tal modo que se reaprovechaban las arcillas refractarias de la localidad, se explotaron las necesidades siderúrgicas mediante la energía fluvial, se pusieron en marcha máquinas hidráulicas que facilitaban el uso del río y además se exportó el producto fuera de Galicia gracias a la proximidad del puerto. De esta forma, durante varias décadas, la primera fábrica, la fundición de Sargadelos, trabajó para el Estado, elaborando material bélico y convirtiéndose en el principal proveedor, llegando a ser distinguida como Real Fábrica, que había recibido en sus orígenes una cesión Real de Carlos IV. Hay que tener en cuenta que Ibáñez era una figura ilustrada conocedora del comercio y la industria, y puso en marcha todos sus conocimientos adquiridos con anterioridad para crear "la primera empresa siderúrgica integral de España" (Sargadelos, 1987, p. 4). Con posterioridad, el interés industrial del Marqués de Sargadelos le llevó a crear en 1804 el primer complejo cerámico y "el primer establecimiento evolucionado de este sector en España que introduce entre otras cosas el decorado mecánico y la loza estampada" (Sargadelos, 1987, p. 7). La materia prima que abundaba en esta zona para la elaboración de la cerámica era el caolín, con la que se consiguió hacer una loza de tipo inglés y producir la loza tipo Bristol. Sargadelos permitió que Galicia figurase entre "las inquietudes transformadoras que sacudían a Europa acompasada a los cambios que se estaban operando en las relaciones de producción" (Sargadelos, 1987, p. 4). Su actividad continuó hasta el cierre de la fábrica en 1875, poniendo fin al establecimiento más evolucionado de España, desapareciendo su huella, pues parece ser que una parte de las fábricas fueron dinamitadas en 1900 para reaprovechar los materiales. Asimismo, la emigración se incrementó en esta zona lucense, pues más de mil familias tuvieron que abandonar Sargadelos tras el cierre de la industria que llegó a atraer a maestros operarios de fuera del país, y decayó drásticamente la reactivación territorial que se había llegado a conseguir años atrás.

Durante la posguerra española la idea empresarial de Sargadelos fue retomada por Isaac Díaz Pardo, reconocido pintor que abandonaría tempranamente esta faceta, dado que su vocación era la arquitectura, para centrarse en la producción de cerámica. En 1948 comenzó a trabajar en un pequeño taller -laboratorio ubicado en el O Castro (Sada, La Coruña), donde hacía piezas únicas que conservaban la huella de su creación a través de materias primas procedentes del norte de Lugo. Era el germen de la antigua cerámica de Sargadelos, que se convertiría en el símbolo del restablecimiento de la memoria gallega, cuya identidad había quedado mermada como consecuencia de la represión franquista, las políticas de incautación y depuración las cuales terminaron con la intelectualidad galleguista, el desmantelamiento del movimiento renovador y la interrupción del Seminario de Estudos Galegos. Es decir, en medio de un panorama cultural desolador, Díaz Pardo consideró que había que recuperar el legado del prestigioso pasado industrial que Galicia llegó a tener, y fue obteniendo el resultado de esa fina porcelana y abriendo los recursos y las posibilidades de esta incipiente empresa. Sin embargo, la venta de estas tierras de Sargadelos a capital alemán en 1955 truncaba el proyecto de Díaz Pardo que encontraba nuevas posibilidades en Argentina, como él mismo llegó a decir: "el caolín gallego, al ponerlo en manos ajenas a Galicia fue la razón que me llevó a la emigración...esta realidad y el hecho de que Perón acababa de caer decidí aceptar una invitación que tenía para hacer una experiencia semejante a la del Castro, y allá me fui..." (Sargadelos, 1987, pp. 131-132), al otro lado del Océano Atlántico, en la Magdalena, a cien kilómetros de Buenos Aires, para levantar una fábrica semejante de cerámica. Esta fábrica comenzó su actividad en 1955 y permitió ampliar los procesos industriales y comerciales de O Castro, que además contó con la colaboración de intelectuales gallegos allí exiliados, como Rafael Dieste, Arturo Cuadrado, Luis Seoane, Núñez Búa, entre otros, quienes y entre todos "se fue concibiendo una posible actuación de propósitos restauradores de la memoria histórica de Galicia que casaban con las ideas que habían hecho posible la experiencia del Castro de Samoedo. Así se fue perfilando una acción empresarial, patriótica y romántica" (Tradición, 1987c, p. 6), y que daría lugar a la creación del Laboratorio de Formas en 1963.

Este contacto supuso un cambio trascendental en Díaz Pardo que fue invitado a participar en una exposición en el Centro Galego de Buenos Aires en 1955, y marcó una nueva etapa en la producción cerámica. Con los intelectuales 
desterrados y galleguistas, trabajó en uno de los temas claves de su trayectoria profesional, la recuperación de "la desmemoria que impuso el régimen que ganó la Guerra Civil, la desinformación sobre todo lo que aconteció la contienda y la posguerra, la tupida comunicación e información sobre lo que ocurría en el mundo" (Seoane, 1990, p. 17). Díaz Pardo se proponía impulsar y dar visibilidad a un capítulo de la historia del país con el apoyo de la España exiliada y silenciada, y la memoria de la tradición gallega tomando como base la cerámica para conocer bien la historia.

De hecho, habría que decir que se establece un doble puente cultural entre el exilio y la España franquista, entre Argentina y Galicia. Por un lado, de carácter geográfico, gracias a las idas y venidas de Díaz Pardo entre el taller de O Castro y la fábrica de la Magdalena; por otro, de tradición, identidad y modernidad que conectan la resurrección de Sargadelos con las nuevas tendencias en diseño industrial, al modo del de Ulm, en Alemania, que dirigía el argentino Maldonado, fundador del Movimiento de Arte Concreto y director de la revista Nueva Visión. La unión de estas conexiones fue la base del denominado El Laboratorio de Formas creado en 1963. Sus principales impulsores, Seoane y Díaz Pardo, eran grandes conocedores de la Bauhaus alemana y de sus aportaciones pioneras, las cuales llegaron a evocar y a seguir de cerca las transformaciones que en esta materia se estaba produciendo por todo el continente europeo. Se trataba de un periodo decisivo donde teóricos como Tomás Maldonado, Bruno Munari o Gillo Dorfles hicieron interesantes reflexiones que dieron lugar a publicaciones como Símbolo, comunicación y consumo. El contacto con estas nuevas corrientes de diseño europeas marcó la segunda etapa de la producción cerámica que originariamente impulsó Díaz Pardo que hasta entonces había estado más próxima temática y estilísticamente a sus experiencias pictóricas, con un gusto por el barroquismo. Posteriormente cambiaría hacia una filosofía del diseño más en consonancia con los conceptos más avanzados del momento. De esta forma, la reproducción de la porcelana fina y transparente de Sargadelos evolucionó estéticamente hacia tendencias más actuales.

\section{Sargadelos: patrimonio cultural y multidisciplinar}

La recuperación de Sargadelos ha fomentado el desarrollo industrial de la zona y la incorporación de sus habitantes a la estructura empresarial, de hecho, en 1987 alcanzaba uno de sus momentos culmen al contar con 250 personas empleadas en la planta de O Cervo y de O Castro. Se tomaba como modelo la reactivación del territorio y la población que había emprendido tiempo atrás Raimundo Ibáñez. Asimismo, se pretendía crear un proyecto interdisciplinar que no solo se limitara a la fabricación de vajilla y porcelana dura, sino que también incluyera "una empresa de artes gráficas, una editorial, dos escuelas de cerámica, un centro de investigación múltiple, un laboratorio y museo geológico, un museo de arte contemporáneo, otro de cerámica popular y moderna. Talleres de cristal, metal y madera; laboratorios fotográficos y audiovisuales; dos auditorios para más de doscientas personas cada uno; salas de proyección; salas de junta y seminarios; estudios individuales; centros de documentación; comedores; bares; salas de exposición, y cinco Galerías de Arte/Librerías de administración directa para extensión de la cultura gallega y portuguesa, en Madrid, Barcelona, Santiago de Compostela, Castro de Samoedo y Sargadelos, en las que se llevan realizando más de dos mil exposiciones, actos culturales, presentación de libros etc." (Tradición, 1987, p. 6). Un momento clave fue la creación del Laboratorio de Formas al que se incorporaba al año siguiente el arquitecto Fernández-Albalat. Luis Seoane viajó a Galicia para concretar el plan de actuación con el núcleo de producción cerámica que seguía activo en el noroeste español, en el taller-laboratorio de Díaz Pardo en O Castro (Sada, La Coruña), y que en la década siguiente esta producción se vería ampliada con la nueva planta circular de Sargadelos construida en O Cervo (Lugo). Así es como el pintor compartía la noticia con Lorenzo Varela:

"En El Castro, Galicia, [...] se ejecuta la más alta calidad actualmente de Europa. Su fundador, el pintor Isaac Díaz Pardo, es el mismo que instaló hace pocos años Celtia, de Magdalena, en la provincia de Buenos Aires. Se aspira además a que en esta gran fábrica funcione en el porvenir un Laboratorio de Formas con destino industrial al modo del de Ulm, en Alemania, que dirige el argentino Maldonado" (Seoane, 1963).

Por tanto, el Laboratorio de Formas era la agrupación de una serie de proyectos, algunos generados en la última etapa de la dictadura franquista, otros impulsados durante la transición democrática; los cuales se basaban en la idea de experimentación, la renovación de las producciones populares, la recuperación del patrimonio material e inmaterial, incorporando emblemas del pasado, de la civilización celtíbera que entroncaban con las costumbres y la memoria. Así, 
por ejemplo, la producción cerámica se abrió a nuevos modelos que hacían una revisión de los elementos principales de la historia gallega a través de las formas celtas, románicas o barrocas. Es decir, se trataba de una evocación directa de la identidad con el convencimiento de que a través del diseño se podría cambiar el mundo, evocar el pasado y restablecer la historia gallega. La recuperación del pasado es el resurgimiento de una historia vivida comunitaria y social que complementa la perspectiva individual. Es en este sentido donde la memoria colectiva tiene un sentido de integración y de relectura de los hechos vividos, salvaguardando las identidades y garantizando la pervivencia de unos valores, impidiendo que caigan en el silencio y en el olvido. Por tanto, historia y memoria van estrechamente unidas en el discurso de recuperación de los acontecimientos pasados, pues a través del recuerdo se consigue resurgir una mirada retrospectiva para reconducir los discursos históricos trazados (Lida, 2009). Este ambicioso proyecto siguió creciendo hasta que derivó en la creación de diversos laboratorios - de comunicación, industria e investigación-, así como en la divulgación de publicaciones sobre la memoria histórica, la creación de espacios artísticos para mostrar el patrimonio exiliado y el arte de vanguardia, junto a centros bibliográficos y documentales. Seguía la organización del centro de investigación basado en interáreas, modelo que había impulsado el prestigioso y desmantelado Seminario de Estudos Galegos. El proyecto de recuperación de la tradición gallega fue un proceso lento que se desarrolló entre Galicia y Argentina, con los allí exiliados y que se materializó en el noroeste español tras el viaje de vuelta de buena parte de los mismos.

El traslado del Laboratorio de Argentina a Galicia tuvo lugar en 1968, desde entonces continúa produciéndose formas y motivos cerámicos que poseen un gran valor artístico. De tal manera que se ha conseguido restaurar una producción industrial que se puso en marcha hace doscientos años y que se ha convertido en símbolo de la identidad y de la memoria gallega. Ese mismo año se trabajó en la creación de una planta experimental que estaba a unos 700 metros de la antigua fábrica siderúrgica de Sargadelos. Cuenta Díaz Pardo que "cuando se pensó en montar el nuevo complejo de Sargadelos se tuvo muy en cuenta el ubicarlo lejos del viejo recinto, conscientes que éramos del respeto que merecía, donde tendrían que ir solamente centros de investigación, museos, formación, etc., pero en el que no se podría situar ningún centro de producción industrial" (Díaz, 1995). Poco después hicieron su propuesta de restauración del citado Seminario de Estudos Galegos que presenta la disyuntiva de haber sido reconvertido durante el franquismo en el Instituto de Estudios Gallegos Padre Sarmiento del CSIC mientras que los exiliados se consideraban los verdaderos continuadores de este centro de investigación, uno de los más importantes de Galicia en el área científico y cultural. Con el intento de mantener la continuidad interrumpida, se realizaron numerosas publicaciones en diferentes áreas y especialidades, como economía, filosofía, biología, ciencias jurídicas, entre otras, buscando la transversalidad interdisciplinar que anteriormente había tenido esta institución. La refundación del Seminario ligado a la comunidad exiliada tuvo lugar en 1972 y estuvo destinado al diseño y la tecnología del grupo Sargadelos, también a la celebración de exposiciones y publicaciones - como el Seminario de Estudios Cerámicos -, o tareas de investigación con el Xeolóxico de Laxe. La creación de las empresas y proyectos dieron lugar a numerosas actividades, experiencias y grupos de trabajo que abordaban la cerámica y la relacionaban con las artes, la historia y la sociedad. Es decir, se fue demostrando "el esfuerzo de integración del artista-artesano en el ciclo de producción, deseando entrar, por vía del diseño, en la transformación de la vida cotidiana, creando objetos útiles, que aportaban a su vez una nueva visión del mundo y del hombre. Del espíritu de la Bauhaus y de las iniciativas mencionadas proceden también las inquietudes por la formación del obrero-artesano-artista, para lograr la democratización de las formas artísticas en el seno de la sociedad" (Seoane, 1990, p. 35).

El diseño integral, siguiendo los postulados de la Bauhaus y de Walter Gropius, está en cada gesto del Laboratorio de Formas, es decir, todos los elementos que componen de la armonía del conjunto al que pertenece, incluida la arquitectura. Además, se consideraba al arquitecto como un diseñador. A mediados de los años cincuenta Sigfried Giedion publicó un texto (Giedion, 1997) donde abogaba por la fusión entre arquitectura moderna y tradición local, una reflexión que se materializó en la fábrica de Sargadelos en O Cervo (Lugo) que fue inaugurada en 1970 y realizada por el arquitecto Fernández-Albalat. En esta obra consiguió desligarse de la estructura arquetípica y creó una planta circular cuyo diseño se adaptaba al entorno y al territorio, evocaba la tradición constructiva gallega con un aporte de modernidad y funcionalidad donde su vinculación con el contexto histórico y social adquiere una importante dimensión. Asimismo, "se convierte en un conjunto de espacios con significado, retomando el ambiente y los materiales de las 
aldeas gallegas, pero sin renunciar a una espacialidad y construcción moderna. Los volúmenes, rotundos y enclavados en el paisaje, se comunican mediante ligeras estructuras metálicas de preciso detalle y herencia constructivista" (Santiago, 2014, p. 4). Abre el camino hacia la modernización arquitectónica gallega poniendo en relación lo local con lo global, la industria con la tecnología, evocando la identidad mediante guiños a aspectos populares y regionales. Otro de los trabajos realizados para el Laboratorio, y que se materializó con los mismos principios, fue la sede del Museo Gallego de Arte Contemporáneo Carlos Maside que corrió a cargo del mismo arquitecto que el complejo de O Castro (Sada) (Real, 2018).

Además, el Laboratorio de Formas solicitó en 1972 la declaración de Conjunto Histórico-Artístico al patrimonio siderúrgico de Sargadelos, siendo ese mismo año declarada su protección. Uno de los antiguos edificios, como la Casa de la Administración, que terminó en ruinas, se consiguió restaurar gracias al Ministerio de Cultura, pues pertenecía al Estado. En 1984, en el complejo de O Cervo, se construyeron nuevas instalaciones que se ajustaban mejor a la producción cerámica dejando la conocida planta circular como centro de experimentación del diseño, talleres de cerámica, madera o metal.

Por otra parte, cabe destacar cómo la industria se convirtió en una de las claves para la reactivación de la memoria. Díaz Pardo y Luis Seoane fueron los primeros en prestar atención a la importancia que esta tenía para la comunicación social en todas sus escalas. De tal manera que, se incorporaban a la cerámica de Sargadelos motivos decorativos con un valor simbólico en la cultura gallega, pues como afirma Antón Patiño "las formas tiene un ADN y una intrahistoria". Estas adquieren formas marinas, la voluta, la espiral, el laberinto de Mogor, la rosa de los vientos, la esvástica de Miño, la roseta, el torque celta o los bajorrelieves de las piedras prehistóricas nórdicas que también fascinaron a Castelao, como también las grafías de los petroglifos. Asimismo, se asimilaron y se popularizaron elementos que estaban presentes en el patrimonio arquitectónico gallego dotándoles de una identidad. Así, recordemos la incorporación de determinados emblemas de la arquitectura popular gallega a la cerámica de Sargadelos, como el decorado Vilar de Donas, procedente del diseño de una puerta de la iglesia románica de esta localidad lucense. También el motivo Cadrelo inspirado en un grabado de piedra de la cultura castrense del siglo VI BP, o el Portomarínico extraído de unas ménsulas de la iglesia románica de San Juan de Porto Marín, sin olvidar Monferico basado en el diseño de los casetones de las bóvedas del Monasterio coruñés de Monfero. Al igual que se recuperaron motivos procedentes de la rejería románica y de las galerías coruñesas, que contribuyeron al resurgimiento de la cultura gallega desde sus orígenes hasta la historia reciente. Estas formas geométricas, símbolos arcaicos, fueron recuperados en la cerámica de Sargadelos (Esteban, 1992), pues no eran "tan abstractos como nos parecen, eran ideografías que representaban imágenes o símbolos, que utilizaban mucho la geometría para logar síntesis comunicativa de fácil identificación" (Díaz, 1987b). Esta iconografía identitaria, que resurge en la segunda mitad del siglo XX, pervive en la actualidad convirtiéndose en un símbolo de Galicia. Sin embargo, no hay que olvidar que esto se debe al esfuerzo de dos intelectuales, Díaz Pardo y Seoane que investigaron cómo crear nuevas formas artísticas a través de la industria cultural, el compromiso y el diseño en base a la tradición. De tal manera que, lo popular, que puede modernizarse "sin abandonar nuestra identidad cultural esencial, con una tradición que es un traspaso de valores que se enriquecen haciéndonos evolucionar" (Seoane, 1970, pp. 120-121).

La cerámica de Sargadelos se convirtió en el soporte de elementos medievales, pues tienen un significado especial. Sobre todo, las 18 jarras que realizó Luis Seoane, para que, según el artista: "los gallegos al mismo tiempo que las utilizamos nos enteremos de que Galicia tiene una historia importante" (Díaz, 1980). Así, por ejemplo, citar las realizadas al Maestro Mateo, a San Rosendo, a Prisciliano, al Rey García de Galicia, a Inés de Castro, o a María Pita, entre otros. $\mathrm{Y}$ a las que se suman las jarras-homenaje dedicadas a personajes de la edad moderna, como fue el caso de Rosalía de Castro, Castelao, Valle-Inclán, Marqués de Sargadelos, Unamuno, Machado o Picasso, también elaboradas por Luis Seoane. Estas primeras piezas figurativas de la recuperada producción cerámica de Sargadelos, se deben al diseño de este último, y que tenían la historia de Galicia como tema principal, en respuesta a "tanto racionalismo falso y descomprometido, y sobre todo ignorante de su propia historia, que se encontró al llegar, como un panorama desolador en el que había desaparecido todo el pasado de Galicia” (Tradición, 1987, p. 6). 


\section{Actuaciones para el reclamo turístico y la expansión del proyecto}

Por otra parte, hay que destacar el impacto social que la cerámica de Sargadelos ha tenido desde sus orígenes, especialmente tras la puesta en marcha en 1972 del Seminario de Sargadelos destinado a estudiar la historia, las formas y también el compuesto químico de la cerámica. De hecho, tras la inauguración de la planta circular en O Cervo, allí se reunieron diseñadores procedentes de todo el mundo, donde se debatió el avance de las tecnologías que paralelamente también se desarrollaron en la sede de O Castro. Buena parte de estas actividades destinadas al reclamo del público fueron promovidas desde esta institución que llevó a cabo la organización de la Escuela Libre y las actividades vinculadas a la tecnología, que reunía anualmente en verano a gente interesada en la materia y procedente de todas las partes del mundo. Asimismo, citar la creación de las Escolas de Cerámica de Castro y Sargadelos, con clases gratuitas a grupos de escolares que han llegado a acoger cada año a más de mil niños. Sin olvidar las experiencias teatrales, presentaciones de libros o la celebración del Seminario sobre diseño, espacio, memoria, arte e industria. De hecho, debido a la integración de la cultura que fomentaba el Laboratorio de Formas, por allí pasaron numerosos intelectuales como Álvaro Cunqueiro, Agustín Ibarrola o José Oteiza, entre otros; además de las actividades de carácter internacional, a través de los "Encontros estivais" que fueron organizados con carácter anual convirtiéndose en un lugar de referencia debido a la multiplicidad de temas que se abordaban: diseño, arte popular o arquitectura, entre otros. Asimismo, se han celebrado numerosos congresos, debates, donde la cerámica tenía una destacada presencia, junto al arte, el diseño o la arquitectura popular.

A todo este amplio programa cultural habría que citar la creación de las Galerías Sargadelos sería otra de las vías de difusión para la venta de esta cerámica pero que, además, funcionaban como galerías de arte y librería. Estas dependían del Departamento de Comunicación que pertenecía, a su vez, al citado Seminario. Son numerosos los actos culturales que en estos espacios se han celebrado, tanto en Galicia - pues había una amplia red de establecimientos por todo el territorio del noroeste español -, como por el resto del país, destacando principalmente las sedes de Madrid y Barcelona.

Actualmente las visitas guiadas se han convertido en un reclamo turístico tanto para el público general como para los interesados en arqueología industrial. Las dos plantas de producción son accesibles, en la del Castro existe la posibilidad de hacer un recorrido por las diferentes fases de creación cerámica que se puede hacer de forma independiente o guiada. Mientras en O Cervo el itinerario está marcado por dos grandes áreas, en primer lugar, la visita al Conjunto Histórico-Artístico de Sargadelos cuyo punto de partida es la contextualización de la antigua fábrica industrial y que se hace a través del Museo Histórico donde se habla del origen y su evolución. Y después, el recorrido se realiza en el exterior por los edificios que componen el complejo sudierúrgico y cerámico, la Casa de la Administración y el área de recreo de las antiguas fábricas. La ruta sigue a novecientos metros, en la actual fábrica de $\mathrm{O}$ Cervo.

\section{Conclusión}

Sargadelos continúa ocupando un lugar destacado tanto en España como en Europa, en el diseño y en la producción industrial de porcelana, llegando a convertirse en una de las empresas más representativas de este ámbito. De hecho, "la empresa sigue proyectándose hoy en día con novedosas ideas que conforman uno de los proyectos más dinámicos y originales de la cerámica española actual" (Mella, 2001, p. 70). Asimismo, se ha convertido en el referente de la innovación y la incorporación tecnológica gracias a los constantes avances que se han venido sucediendo desde sus inicios a finales de los años cuarenta. Un progreso que se hace sin olvidar los elementos claves de su fundación: mantener el valor identitario, la tradición, los orígenes gallegos y el enraizamiento en el territorio, pues la materia prima, el caolín, sale de las arcillas gallegas. La cultura ha sido una de las claves del proyecto, motivo por el cual se ha dado una gran prioridad a las actividades emprendidas como reclamo de la sociedad, desarrollando una "importante labor de difusión y promoción de la cultura gallega; en especial, de los talentos más recientes y destacados del arte y la literatura" (Mella, 2001, p. 71). Asimismo citar, el reclamo turístico a través de las visitas guiadas que se realizan a las dos plantas de producción cerámica.

Sin embargo, en los últimos años Sargadelos ha sido objeto de polémica, pues las desavenencias entre sus socios y la búsqueda de mayores beneficios económicos han ocasionado la pérdida de valores que formaban parte de los orígenes 
de esta empresa que ha incluso amenazado con el cierre de las fábricas y el despido de la plantilla. Una crisis que ha generado el declive del complejo industrial del Laboratorio de Formas que ha dejado de representar el entramado interdisciplinar e institucional que en su momento impulsó, cuyo fin era rescatar la memoria histórica. Por tanto, queda ya lejos el esplendor que en su día alcanzó este proyecto impulsado por Isaac Díaz Pardo y Luis Seoane, pues ahora preocupa más la comercialización de la cerámica y los beneficios económicos. Motivo por el cual se han incorporado firmas de diseñadores reconocidos, pero se ha desvinculado del compromiso político, social y memorial que en su día llegó a tener. A día de hoy, Sargadelos sigue siendo un símbolo de Galicia gracias a todo el trabajo que hubo detrás durante décadas, influido por las corrientes de diseño procedentes de Argentina y de Alemania, que llegaron a Galicia por la vía de los intelectuales exiliados que retroalimentaron con sus ideas esta cerámica identitaria.

\section{Referencias}

Díaz Arias de Castro, X., Muñoz Fontenla, L., y Rodríguez, J. (2001). Arte/industria. Isaac Díaz Pardo. Santiago de Compostela: Colegio Oficial de Arquitectos de Galicia.

Díaz Pardo, I. (1980, 31 de mayo). Luis Seoane e Sargadelos. En La Región.

Díaz Pardo, I. (1987a). Galicia Hoy. Sada (La Coruña): Ediciós do Castro.

Díaz Pardo, I. (1987b). Xustificación do distintivo que fixen para o IV Centenario de María Pita. En Díaz Pardo, I. Galicia Hoy. Sada (La Coruña): Ediciós do Castro.

Díaz Pardo, I. (1995, 2 de septiembre). La restauración de Sargadelos. En La voz de Galicia.

Esteban Gómez, T. (1992). Evolución y cambio de las formas cerámicas en Sargadelos: orígenes y características de la empresa cerámica sargadeliana. Tesis Doctoral. Madrid: Universidad Complutense de Madrid.

Giedion, S. (1997). Escritos escogidos. Murcia: Colegio Oficial de Aparejadores y Arquitectos Técnicos.

http://consellodacultura.gal/fondos_documentais/epistolarios/epistolario.php?epistolario $=1651$

Lida, C.E. (2009). Caleidoscopio del exilio. Actores, memoria e identidades. México, D.F.: El Colegio de México. Centro de Estudios Históricos.

Luis Seoane, o L.F. e os emprendimentos do Castro de Samoedo e Sargadelos. (1987). En Tradición e futuro. Sada (La Coruna): Ediciós do Castro.

Mella Márquez, J. M. (2011). Sargadelos. En J. M. Mella Márquez (Ed.), La innovación en la cerámica artesanal (pp. 70-84). Madrid: Subdirección General de Desarrollo Normativo, Informes y Publicaciones.

Prado Gómez, A. (1993-1994). Sargadelos, una experiencia ilustrada precapitalista. Boletín do Museo Provincial de Lugo, 6, $29-51$.

Real López, I. (2018). El Museo Gallego de Arte Contemporáneo Carlos Maside. Memoria, compromiso e identidad. Gijón: Trea.

Santiago Río, A. (2014). El Laboratorio de Formas de Galicia: reconstruyendo la identidad regional a través de la arquitectura. ZARCH, Journal of interdisciplinary Studies in Architecture and Urbanism, 3, 30-41.

Sargadelos. Un modelo de emprendimento creado por Ibáñez. (1987) En, Tradición e futuro. Sada (La Coruña): Ediciós do Castro.

Seoane, L. (1963, 8 de agosto). Carta de Luis Seoane a Lorenzo Varela, El Castro. En Fondos Documentais Consello da Cultura Galega. Fundación Luis $\quad$ Seoane. Disponible en http://consellodacultura.gal/fondos_documentais/epistolarios/epistolario.php?epistolario=1651

Seoane, L. (1970). Hacia un diseño que considere las particularidades de cada país. En Cadernos do Laboratorio de Formas, 1, 120121.

Seoane, X. (1990). Isaac Díaz Pardo: Un proxecto socio-cultural para Galicia. Santiago de Compostela: Concello.

Soneira Beloso, B. (2007). Unha ollada ó Laboratorio de Formas ós 44 anos da súa creación. Cadernos Laboratorio de Formas 11.

Tradición e futuro. (1987). Sada (La Coruña): Ediciós do Castro. 